\title{
Comparison of intravascular ultrasound guided versus angiography guided drug eluting stent implantation: a systematic review and meta-analysis
}

Yao-Jun Zhang ${ }^{1 \dagger}$, Si Pang ${ }^{1,2+}$, Xiao-Yun Chen ${ }^{1,2+}$, Christos V. Bourantas ${ }^{3}$, Dao-Rong Pan ${ }^{1}$, Sheng-Jie Dong ${ }^{4}$, Wen Wu', Xiao-Min Ren ${ }^{1}$, Hao Zhu' ${ }^{1}$, Shun-Yi Shi ${ }^{1}$, Javaid Iqbal ${ }^{5}$, Bill D. Gogas ${ }^{6}$, Bo Xu ${ }^{7}$ and Shao-Liang Chen ${ }^{1,8^{*}}$

\begin{abstract}
Background: Intravascular ultrasound (IVUS) can be a useful tool during drug-eluting stents (DES) implantation as it allows accurate assessment of lesion severity and optimal treatment planning. However, numerous reports have shown that IVUS guided percutaneous coronary intervention is not associated with improved clinical outcomes, especially in non-complex patients and lesions.

Methods: We searched the literature in Medline, the Cochrane Library, and other internet sources to identify studies that compare clinical outcomes between IVUS-guided and angiography-guided DES implantation. Random-effects model was used to assess treatment effect.

Results: Twenty eligible studies with a total of 29,068 patients were included in this meta-analysis. The use of IVUS was associated with significant reductions in major adverse cardiovascular events (MACE, odds ratios [OR] 0.77, $95 \%$ confidence intervals [Cl] 0.71-0.83, $P<0.001)$, death (OR 0.62, $95 \% \mathrm{Cl} 0.54-0.71, p<0.001)$, and stent thrombosis (OR 0.59, $95 \% \mathrm{Cl}: 0.47-0.73, P<0.001)$. The benefit was also seen in the repeated analysis of matched and randomized studies. In stratified analysis, IVUS guidance appeared to be beneficial not only in patients with complex lesions or acute coronary syndromes (ACS) but also patients with mixed lesions or presentations (MACE: OR 0.69, 95 \% Cl: 0.60-0.79, $p<0.001$, OR 0.81, $95 \%$ Cl 0.74-0.90, $p<0.001$, respectively). By employing meta-regression analysis, the benefit of IVUS is significantly pronounced in patients with complex lesions or ACS with respect to death $(p=0.048)$.
\end{abstract}

Conclusions: IVUS guidance was associated with improved clinical outcomes, especially in patients with complex lesions admitted with ACS. Large, randomized clinical trials are warranted to identify populations and lesion characteristics where IVUS guidance would be associated with better outcomes.

Keywords: Intravascular ultrasound, Angiography, Drug-eluting stent, Meta-analysis

\footnotetext{
* Correspondence: chmengx126@gmail.com

${ }^{\dagger}$ Equal contributors

'Department of Cardiology, Nanjing First Hospital, Nanjing Medical

University, Nanjing, China

${ }^{8}$ Nanjing First Hospital, Nanjing Medical University, No. 68, Changle Road,

210006 Nanjing, Jiangsu, China

Full list of author information is available at the end of the article
}

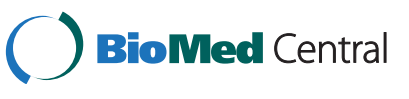

(c) 2015 Zhang et al. Open Access This article is distributed under the terms of the Creative Commons Attribution 4.0 International License (http://creativecommons.org/licenses/by/4.0/), which permits unrestricted use, distribution, and reproduction in any medium, provided you give appropriate credit to the original author(s) and the source, provide a link to the Creative Commons license, and indicate if changes were made. The Creative Commons Public Domain Dedication waiver (http://creativecommons.org/publicdomain/zero/1.0/) applies to the data made available in this article, unless otherwise stated. 


\section{Background}

Although there is evidence about the efficacy of drugeluting stents (DES) for treating coronary artery disease, patients are not free of events as there is a considerable risk of restenosis and stent thrombosis (ST) after DES implantation [1]. Intravascular ultrasound (IVUS) with its high resolution appears as a useful tool for evaluating lesion severity, optimizing stent implantation and subsequently reducing adverse cardiovascular events $[2,3]$. However, due to lack of universally identical IVUS guidance criteria and large randomized clinical trials, the use of IVUS for guiding DES implantation has been a controversial issue among the interventionlists, with many of them believing that its use increases cost and has only a limited clinical benefit.

The results observed in a prespecified substudy of ADAPT-DES (Assessment of Dual Antiplatelet Therapy With Drug-Eluting Stents) showed that IVUS guidance was strongly associated with lower incidences of ST, myocardial infarction (MI) and major adverse cardiac events (MACE) in all-comers population at 1 year follow-up [4]. The improved outcomes noted in the IVUS-guided group have been attributed to the longer and lager stents used in the IVUS guidance group. However, a recent large observational study reported that IVUS-guided percutaneous coronary intervention (PCI) was not associated with improved long-term survival compared with standard angiography-guided PCI [5]. The differences in outcomes noted in different studies reflect the undefined role of IVUS during PCI in clinical practice. Although meta-analyses have shown better outcomes in patients undergoing IVUS guided PCI [6-8], to date, there are limited data comparing IVUS guidance with angiography guidance PCI in patients with complex lesions or acute coronary syndromes (ACS).

Therefore, in this study we update our previous metaanalysis and perform subgroup analysis with matched and randomized studies and assess the effect on clinical outcomes of IVUS guidance. We further investigate whether IVUS guided DES implantation is associated with a greater benefit in patients with complex lesions or ACS.

\section{Methods}

\section{Data sources and search strategy}

We conducted the meta-analysis in accordance with the PRISMA (Preferred Reporting Items for Systematic reviews and Meta-Analyses) statement for studies that evaluate healthcare interventions [9]. We searched the literature in Medline, the Cochrane Library from January 1995 to October 2014, using combinations of the medical subject headings "ultrasound, intravascular", "IVUS", "IVUS-guided", "angiography", "angiography-guided", "drug-eluting stent" and "DES". We used the Science
Citation Index as a cross reference to include studies that met the search criteria. We also searched potential studies from the conference proceedings of the American College of Cardiology, the American Heart Association, the European Society of Cardiology and the Transcatheter Cardiovascular Therapeutics. Additionally, we reviewed the reference of the selected articles and earlier metaanalyses for related documents.

\section{Study identification and data extraction}

Two investigators (PS and CXY) independently conducted the literature search, data extraction and quality evaluation through a standard method. Differences were resolved by consensus with third investigator (ZYJ). Studies were included in the current meta-analysis if they met the following predetermined criteria [4, 10-28]: (1) clinical research published in peer-reviewed journals with complete data; (2) comparison of IVUS- versus angiography-guided DES implantation; and (3) at least 6 months follow up. Studies that included bare metal stents (BMS) and DES implantation and did not provide separately the DES data were excluded. Two investigators (PS and CXY) extracted the baseline information, which included the study name, study design, sample size, follow-up duration, patients' baseline characteristics (mean age, sex distribution, and risk factors), lesion and procedural characteristics, and clinical outcomes. The Newcastle-Ottawa-Scale (NOS) scale was used for quality assessment, including assessment of selection of the exposed and unexposed cohort, comparability of the two cohorts, and outcome assessment [29]. The qualities of randomized trials were assessed by the Jadad score [30].

\section{Clinical endpoints}

The endpoints of the present analysis included: (1) allcause death (in 2 studies [11, 13] that only reported cardiac death was included instead), (2) MACE, (3) ST (definite or probable ST, according to the definition of the Academic Research Consortium), (4) MI (in 1 study [14] only the Q-wave MI was reported while others reported both non-Q-wave MI and Q-wave MI), (5) target vessel revascularization (TVR), and (6) target lesion revascularization (TLR). Repeated-analyses were performed in patients with complex lesions or ACS compared to mixed lesions or any presentations and among propensitymatched and randomized studies.

\section{Statistical analysis}

The guideline of the Cochrane Handbook for Systematic Reviews of Interventions was implemented in this metaanalysis [31]. Standard data extraction and calculation were used to improve efficiency and reliability of the analysis [32]. Random-effects model was adopted to measure overall treatment effect expressed as odds ratios 
(OR) and $95 \%$ confidence intervals (CI). Forest plots were generated for graphical presentations of clinical outcomes with IVUS- versus angiography-guided groups. We assessed heterogeneity of the study using chi-square tests $(p>0.1$ showed no significant heterogeneity among studies) and $I^{2}$ statistic $\left(I^{2}>25 \%,>50 \%,>75 \%\right.$ showed low, moderate and severe heterogeneity, respectively). All p-values were two-tailed and the statistical significance was considered at $<0.05$. In case there was heterogeneity among the studies, we conducted sensitivity analyses to clear the source of the heterogeneity. We tested the interaction between patients with complex lesions or ACS versus patients with mixed lesions or any clinical presentations by means of weighted least squares random-effect meta-regression, with weighting provided by the inverse of the variance of each study, patients with complex lesions or ACS (coded as 1 versus patients with mixed or any clinical presentations coded as 0) as random factor, and the natural logarithm of the individual OR as dependent variable [29]. The Egger's linear regression test was performed for asymmetry of the publication or reporting bias [33]. All statistical analysis was performed with STATA 12.0 (Stata Corp, College Station, TX, USA).

\section{Ethics}

This meta-analysis didn't require ethical approval.

\section{Results}

\section{Inclusion of studies}

In total, twenty eligible studies were included in this meta-analysis (Fig. 1). Out of 20 studies, 3 studies were prospective, randomized trials [10-12], and 17 were observational registries $[4,13-28]$. In addition, 9 of the included studies had performed sub-analysis after propensity score matching $[14,15,17,18,20,21,26-$ 28]. Therefore, 13 studies enrolled only patients with complex lesions or ACS, including 4 for left main disease [13, 15, 26, 28], 3 for bifurcation $[16,17,21], 1$ for chronic total occlusion (CTO) [27], 1 for long lesion [12], 1 for ST-segment elevation MI [24], and 3 for combined complex lesions [10, 11, 24].

Out of 29,068 patients included in this study, 13,552 (46.6\%) patients underwent IVUS-guided DES implantation and 15,516 (53.4\%) angiography-guided DES implantation. The study characteristics are summarized in Table 1 . The mean weighted follow-up was 20.8 months. Lesion and procedural characteristics are shown in Table 2.

\section{Effect of IVUS guidance on clinical outcomes}

MACE were reported in 19 of the 20 included studies. The summary result was in favor of IVUS-guided DES implantation in risk of MACE (OR 0.77, $95 \%$ CI 0.71$0.83, P<0.001$; Fig. 2a). Statistical analysis did not show

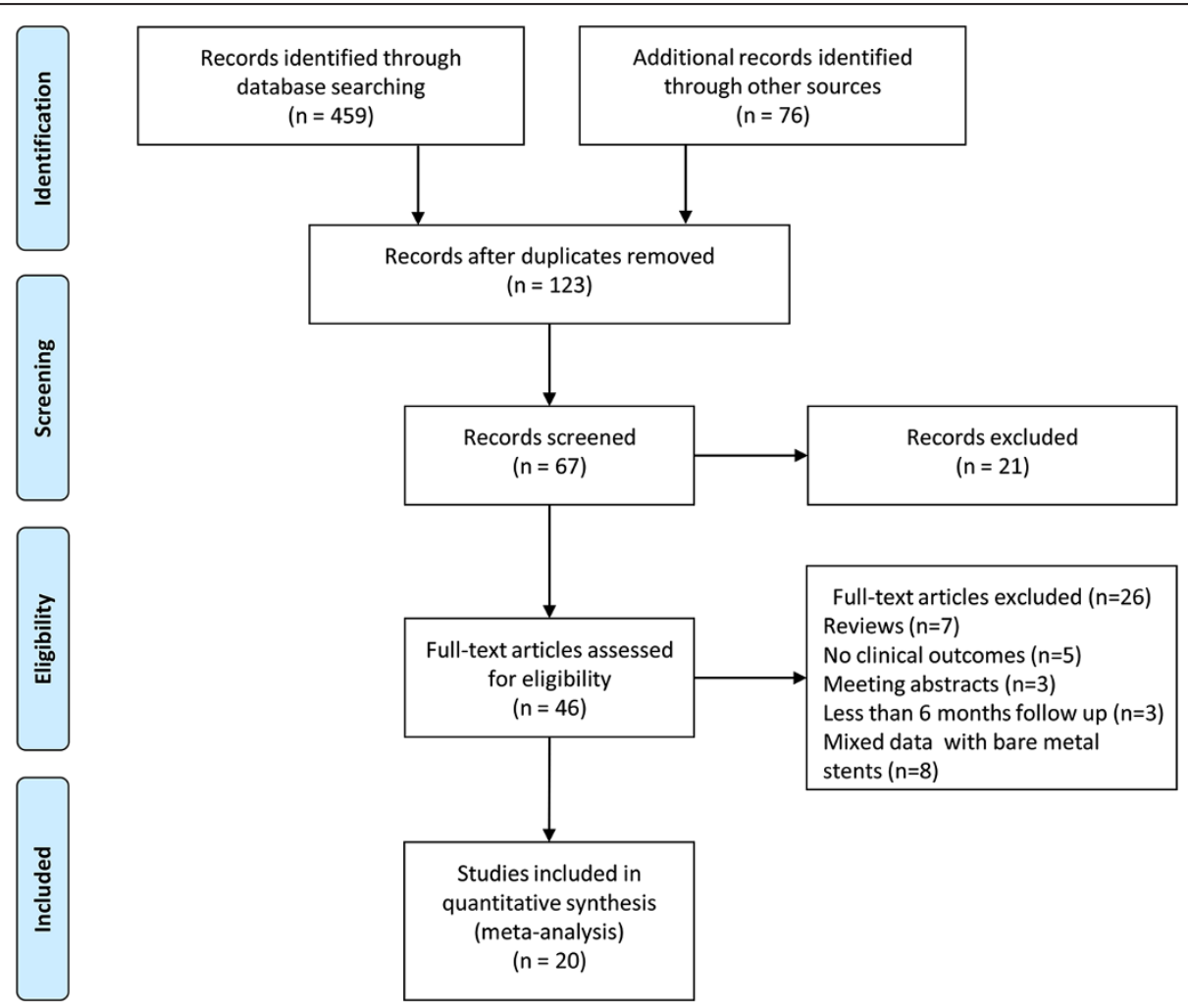

Fig. 1 Flow diagram of meta-analysis 
Table 1 Study design and baseline characteristics

\begin{tabular}{|c|c|c|c|c|c|c|c|c|c|c|c|c|}
\hline Study & Year & Design & Sample size & F/U Months & Age years & Male & DM & Hyperlipidemia & LVEF, \% & Renal insufficiency & Smoker & $\begin{array}{l}\text { Study quality } \\
(\operatorname{Max}=9)\end{array}$ \\
\hline P Agostoni [13] & 2005 & Observational & $24 / 34$ & 14 & $62 / 64$ & $15 / 25$ & $9 / 10$ & $15 / 23$ & $52 / 44$ & NA/NA & $4 / 7$ & 7 \\
\hline P Roy [14] & 2008 & Observational & $884 / 884$ & 12 & $66 / 66$ & $613 / 619$ & $317 / 304$ & $762 / 770$ & $47 / 48$ & $110 / 112$ & $186 / 181$ & 9 \\
\hline SJ Park [15] & 2009 & Observational & $145 / 145$ & 36 & $64 / 65$ & $102 / 102$ & $49 / 49$ & $42 / 44$ & $60 / 61$ & $7 / 6$ & $28 / 30$ & 9 \\
\hline SH Kim [16] & 2010 & Observational & $308 / 112$ & 48 & $59 / 60$ & $221 / 80$ & $61 / 24$ & $134 / 99$ & $60 / 59$ & $3 / 1$ & $109 / 40$ & 8 \\
\hline J Jakabcin [10] & 2010 & $\mathrm{RCT}$ & $105 / 105$ & 18 & $59 / 60$ & $77 / 75$ & $44 / 47$ & $66 / 69$ & NA/NA & NA/NA & $42 / 37$ & $4^{\mathrm{a}}$ \\
\hline JS Kim [17] & 2011 & Observational & $487 / 487$ & 36 & $62 / 62$ & $324 / 326$ & $155 / 162$ & $168 / 170$ & $60 / 59$ & $15 / 15$ & 106/111 & 9 \\
\hline BE Claessen [18] & 2011 & Observational & $631 / 873$ & 24 & $64 / 65$ & $469 / 652$ & $190 / 316$ & $533 / 740$ & NA/NA & $54 / 97$ & $70 / 94$ & 9 \\
\hline SH Hur [19] & 2011 & Observational & 2765/1816 & 36 & $59 / 62$ & $1982 / 1240$ & $622 / 463$ & $1305 / 1108$ & $59 / 57$ & $83 / 105$ & 979/636 & 7 \\
\hline KW Park [20] & 2012 & Observational & $619 / 802$ & 12 & $62 / 63$ & $393 / 524$ & $233 / 309$ & $468 / 610$ & NA/NA & NA/NA & $147 / 233$ & 8 \\
\hline SL Chen [21] & 2012 & Observational & $324 / 304$ & 12 & $63 / 65$ & $261 / 227$ & $60 / 54$ & $108 / 304$ & $61 / 60$ & NA/NA & $147 / 154$ & 8 \\
\hline ADAPT-DES [4] & 2013 & Observational & $3349 / 5234$ & 12 & $63 / 64$ & $2457 / 3901$ & 1048/1735 & $2287 / 4093$ & NA/NA & $536 / 894$ & $851 / 1088$ & 9 \\
\hline Chieffo A [11] & 2013 & RCT & $142 / 142$ & 24 & $64 / 64$ & $117 / 109$ & $34 / 38$ & $100 / 109$ & $55 / 56$ & NA/NA & $49 / 44$ & $4^{\mathrm{a}}$ \\
\hline RESET [12] & 2013 & $\mathrm{RCT}$ & $269 / 274$ & 12 & $63 / 64$ & $177 / 150$ & $85 / 82$ & $165 / 165$ & $55 / 54$ & NA/NA & $58 / 47$ & $5^{a}$ \\
\hline YJ Youn [22] & 2011 & Observational & $125 / 216$ & 36 & $60 / 61$ & $93 / 136$ & $34 / 71$ & $28 / 24$ & $45 / 48$ & $3 / 6$ & $94 / 125$ & 8 \\
\hline YW Yoon [23] & 2013 & Observational & $662 / 912$ & 12 & $61 / 63$ & $428 / 592$ & $184 / 270$ & $403 / 512$ & NA/NA & NA/NA & $167 / 236$ & 8 \\
\hline SG Ahn [24] & 2013 & Observational & $49 / 36$ & 24 & $65 / 65$ & $30 / 22$ & $13 / 11$ & $14 / 9$ & $54 / 56$ & $5 / 2$ & $16 / 14$ & 7 \\
\hline IRIS-DES [25] & 2013 & Observational & $1616 / 1628$ & 24 & $62 / 64$ & $1115 / 1034$ & $500 / 516$ & $645 / 548$ & $60 / 59$ & $48 / 57$ & $492 / 478$ & 7 \\
\hline Hernandez [26] & 2014 & Observational & $505 / 505$ & 36 & $66 / 67$ & $404 / 397$ & $183 / 175$ & $314 / 284$ & $55 / 55$ & $35 / 31$ & $148 / 161$ & 8 \\
\hline SJ Hong [27] & 2014 & Observational & $206 / 328$ & 24 & $62 / 63$ & $159 / 234$ & $62 / 124$ & $89 / 116$ & NA/NA & NA/NA & $58 / 93$ & 9 \\
\hline XF Gao [28] & 2014 & Observational & $337 / 679$ & 12 & $66 / 67$ & $274 / 526$ & 109/232 & $228 / 487$ & $59 / 57$ & $88 / 214$ & $111 / 230$ & 9 \\
\hline
\end{tabular}

Data are presented as IVUS guidance/ angiography guidance. The Newcastle-Ottawa-Scale was used for quality assessment of observational studies

Abbreviation: DM diabetes mellitus; F/U follow-up; LVEF left ventricular ejection fraction; $M I$ myocardial infarction; NA not available; $R C T$ randomized controlled trials

aThe qualities of included randomized trials were assessed by the Jadad score 
Table 2 Patient, lesion, and procedural characteristics

\begin{tabular}{|c|c|c|c|c|c|c|c|c|c|}
\hline Study & Lesion number & $\mathrm{LM}$ & $\mathrm{LAD}$ & LCX & $\mathrm{RCA}$ & Ostial lesion & Stent number & Stent diameter & Stent length \\
\hline P Agostoni [13] & NA/NA & $24 / 34$ & $0 / 0$ & $0 / 0$ & $0 / 0$ & $7 / 3$ & $1.5 / 1.4$ & $3.2 / 3.2$ & $27 / 23$ \\
\hline P Roy [14] & $1.7 / 1.7$ & $26 / 30$ & $427 / 433$ & $320 / 305$ & $446 / 450$ & $50 / 48$ & $1.5 / 1.5$ & $3.05 / 3.09$ & $20.7 / 20.1$ \\
\hline SJ Park [15] & NA/NA & $145 / 145$ & $0 / 0$ & $0 / 0$ & $75 / 80$ & $61 / 62$ & $1.23 / 1.24$ & NA/NA & $35.2 / 35.6$ \\
\hline SH Kim [16] & $1.4 / 1.2$ & NA/NA & NA/NA & NA/NA & NA/NA & $61 / 9$ & NA/NA & NA/NA & $34 / 26$ \\
\hline J Jakabcin [10] & $1.2 / 1.2$ & $3 / 4$ & $59 / 57$ & $12 / 16$ & $30 / 25$ & NA/NA & NA/NA & NA/NA & 23.6/22.1 \\
\hline JS Kim [17] & NA/NA & $17 / 19$ & $404 / 402$ & $63 / 63$ & $20 / 22$ & NA/NA & $1.3 / 1.2$ & NA/NA & NA/NA \\
\hline BE Claessen [18] & $1.9 / 1.8$ & $30 / 20$ & $349 / 321$ & $226 / 307$ & $165 / 316$ & $55 / 59$ & NA/NA & $3.1 / 3.0$ & $23.5 / 24.5$ \\
\hline SH Hur [19] & NA/NA & $232 / 45$ & $1628 / 904$ & $340 / 390$ & $686 / 612$ & $312 / 84$ & $1.7 / 1.6$ & $3.3 / 3.1$ & $38.6 / 36.7$ \\
\hline KW Park [20] & $1.4 / 1.3$ & $0 / 0$ & $455 / 502$ & $171 / 250$ & $227 / 315$ & NA/NA & $1.3 / 1.2$ & $3.19 / 3.06$ & $30.7 / 23.0$ \\
\hline SL Chen [21] & NA/NA & $137 / 83$ & 129/186 & $44 / 26$ & $14 / 9$ & NA/NA & $1.26 / 1.20$ & $3.25 / 3.16$ & $32.7 / 30.5$ \\
\hline ADAPT-DES [4] & $1.48 / 1.52$ & $146 / 171$ & NA/NA & NA/NA & NA/NA & NA/NA & 1.73/1.71 & NA/NA & $33.6 / 31.7$ \\
\hline Chieffo A [11] & NA/NA & NA/NA & NA/NA & NA/NA & NA/NA & NA/NA & NA/NA & $2.95 / 2.86$ & 23.9/23.2 \\
\hline RESET [12] & NA/NA & $0 / 0$ & $167 / 185$ & $41 / 35$ & $61 / 54$ & NA/NA & NA/NA & NA/NA & $32.4 / 32.3$ \\
\hline YJ Youn [22] & NA/NA & $1 / 2$ & $75 / 101$ & $7 / 21$ & $42 / 92$ & NA/NA & $1.4 / 1.2$ & $3.18 / 3.03$ & $34.8 / 29.5$ \\
\hline YW Yoon [23] & NA/NA & $0 / 0$ & $441 / 566$ & $131 / 255$ & $163 / 344$ & NA/NA & NA/NA & NA/NA & 20.4/20.1 \\
\hline SG Ahn [24] & NA/NA & $0 / 0$ & 29/16 & $6 / 2$ & $14 / 18$ & $8 / 2$ & $2.8 / 2.2$ & $3 / 2.87$ & $74 / 66$ \\
\hline IRIS-DES [25] & NA/NA & $148 / 26$ & 1019/958 & NA/NA & NA/NA & NA/NA & $1.44 / 1.16$ & $3.28 / 3.1$ & $35.5 / 26.9$ \\
\hline Hernandez [26] & $1.47 / 1.5$ & $505 / 505$ & NA/NA & NA/NA & NA/NA & $151 / 145$ & NA/NA & NA/NA & NA/NA \\
\hline SJ Hong [27] & NA/NA & $6 / 4$ & $91 / 123$ & $34 / 75$ & NA/NA & NA/NA & $1.7 / 1.42$ & $2.96 / 2.83$ & $44.6 / 36.9$ \\
\hline XF Gao [28] & $1.2 / 1.3$ & $337 / 679$ & $224 / 479$ & $125 / 324$ & $146 / 369$ & $32 / 59$ & $1.5 / 1.4$ & $3.5 / 3.4$ & $35.4 / 33.3$ \\
\hline
\end{tabular}

Data are presented as IVUS guidance/ angiography guidance

Abbreviation: $L M$ left main coronary artery; $L A D$ left anterior descending artery; $L C X$ left circumflex artery; $R C A$ right coronary artery; $N A$ not available

significant heterogeneity (heterogeneity chi-square $=23.40$, $\mathrm{I}^{2}=23.1 \%, p=0.176$ ).

IVUS guidance was associated with a significantly low risk of mortality, compared with angiography guidance (OR 0.62, 95 \% CI 0.54-0.71, $p<0.001$; Fig. 2b). Evidence of statistical heterogeneity was not observed among the studies (heterogeneity chi-square $=22.77, \mathrm{I}^{2}=20.9 \%$, $p=0.200)$.

The occurrence of definite/probable ST was reported in 19 studies. IVUS guidance appeared to be associated with a significantly low incidence of ST (OR 0.59, $95 \%$ CI: $0.47-0.73, P<0.001$; Fig. 2c). There is no statistical heterogeneity in these studies (heterogeneity chi-square $=$ $\left.19.37, \mathrm{I}^{2}=12.2 \%, p=0.308\right)$.

MI was reported in 18 studies and the pooled result showed that IVUS guidance was associated with a significantly low risk of MI (OR 0.64, 95 \% CI: 0.55-0.75, P< 0.001; Fig. $2 \mathrm{~d}$ ). The pooled OR for TLR associated with IVUS guidance versus angiography guidance was 0.81 (95 \% CI: $0.69-0.94, P=0.005$; Fig. 2e) while the pooled OR for TVR was 0.86 (95\% CI: 0.77-0.97, $P=0.012$; Fig. 2f). Statistical heterogeneity was not found in MI (heterogeneity chi-square $\left.=16.80, \mathrm{I}^{2}=4.8 \%, p=0.398\right)$, but there was heterogeneity in TLR and TVR (heterogeneity chisquare $=20.27, \mathrm{I}^{2}=45.7 \%, p=0.042$; heterogeneity chisquare $=24.33, \mathrm{I}^{2}=46.6 \%, p=0.028$, respectively).
Outcomes in propensity-matched and randomized studies In the repeated analysis of propensity-matched and randomized studies, a total of 8,331 patients were included. Repeated analysis confirmed that IVUS guidance was associated with a significant reductions in MACE (OR 0.79, $95 \%$ CI: 0.70-0.88, $P<0.001$, Fig. 3a), death (OR 0.64, 95 \% CI: 0.52-0.79, $P<0.001$, Fig. 3b), ST (OR 0.55, 95 \% CI: 0.39-0.78, $P=0.001$, Fig. 3c), MI (OR 0.69, $95 \%$ CI: $0.56-0.85, P<0.001$, Fig. $3 \mathrm{~d}$ ), and TVR (OR 0.82, 95 \% CI: $0.68-0.98, P=0.028$, Fig. 3f). No statistical difference was observed in TLR (OR 0.92, 95 \% CI: 0.761.11, $P=0.377$, Fig. 3e).

\section{Stratified analysis in patients with complex lesions or ACS}

Sub-analysis was performed to compare IVUS-guided versus angiography-guided PCI with DES for patients with complex lesions or ACS. Thirteen studies with 6,393 patients were eligible for this sub-analysis. IVUS guidance was associated with a low risk of MACE (OR 0.69, $95 \%$ CI: $0.60-0.79, p<0.001$ ), death (OR 0.52, 95 \% CI: 0.40$0.67, p<0.001$ ), and ST (OR 0.41, 95 \% CI: 0.25-0.69, $p=$ 0.001 ) for patients with complex lesions or ACS, when compared to patients with mixed lesions or any clinical presentation (MACE [OR 0.81, $95 \%$ CI: 0.74-0.90, $p<$ 0.001], death [OR 0.67, $95 \%$ CI: 0.56-0.80, $p<0.001$ ], and ST [OR 0.64, 95 \% CI: 0.50-0.82, $p<0.001$ ], respectively) 
A

\begin{tabular}{|c|c|c|c|c|}
\hline Study & Year & MACE & $\mathrm{OR}(95 \% \mathrm{Cl})$ & Weight $\%$ \\
\hline P Agostoni [13] & 2005 & $\rightarrow$ & $0.40(0.05,2.91)$ & 0.17 \\
\hline P Roy [14] & 2008 & $\rightarrow$ & $0.90(0.71,1.15)$ & 11.13 \\
\hline SJ Park [15] & 2009 & & $0.64(0.39,1.05)$ & 2.75 \\
\hline J Jakabcin [10] & 2010 & $\rightarrow$ & $0.92(0.48,1.76)$ & 1.58 \\
\hline JS Kim [17] & 2011 & & $0.73(0.44,1.20)$ & 2.68 \\
\hline BE Claessen [18] & ] 2011 & $\rightarrow$ & $0.79(0.63,1.00)$ & 12.41 \\
\hline SH Hur [19] & 2011 & $\rightarrow$ & $0.85(0.71,1.02)$ & 19.70 \\
\hline KW Park [20] & 2012 & $T$ & $1.43(0.88,2.33)$ & 2.79 \\
\hline SL Chen [21] & 2012 & & $0.80(0.54,1.18)$ & 4.31 \\
\hline ADAPT-DES [4] & 2012 & $\rightarrow$ & $0.67(0.53,0.84)$ & 12.49 \\
\hline Chieffo A [11] & 2013 & & $0.73(0.41,1.28)$ & 2.07 \\
\hline RESET [12] & 2013 & & $0.59(0.28,1.24)$ & 1.20 \\
\hline YJ Youn [22] & 2011 & $\rightarrow$ & $0.71(0.40,1.25)$ & 2.10 \\
\hline YW Yoon [23] & 2013 & & $1.06(0.54,2.08)$ & 1.46 \\
\hline SG Ahn [24] & 2013 & & $0.24(0.07,0.80)$ & 0.45 \\
\hline IRIS-DES [25] & 2013 & $\rightarrow-1$ & $0.64(0.44,0.94)$ & 4.60 \\
\hline Hernandez [26] & 2014 & $\rightarrow$ & $0.73(0.55,0.96)$ & 8.54 \\
\hline SJ Hong [27] & 2014 & $\rightarrow$ & $0.92(0.55,1.53)$ & 2.54 \\
\hline XF Gao [28] & 2014 & $\rightarrow$ & $0.54(0.40,0.73)$ & 7.05 \\
\hline \multicolumn{2}{|c|}{ Overall (1-squared $=23.1 \%, p=0.176$ ) } & $\theta$ & $0.77(0.71,0.83)$ & 100.00 \\
\hline & 0.01 & 1 & 00 & \\
\hline
\end{tabular}

C

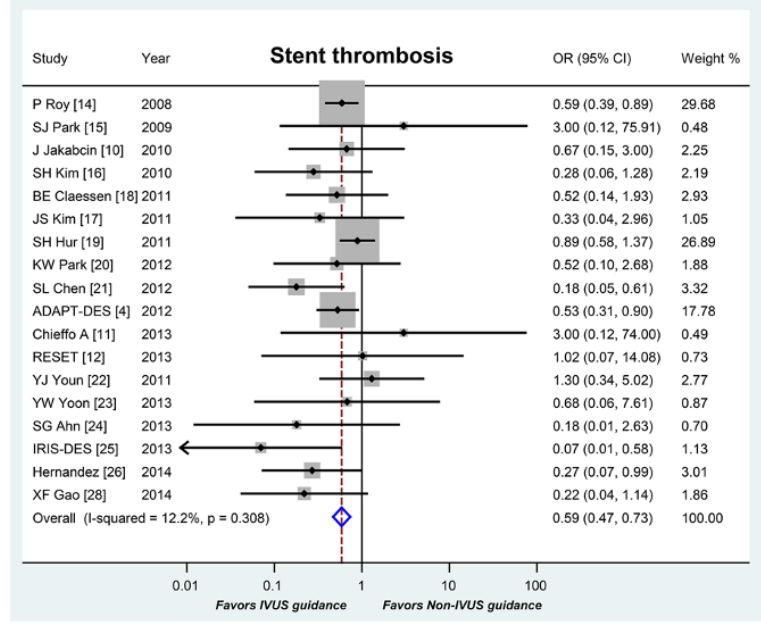

E

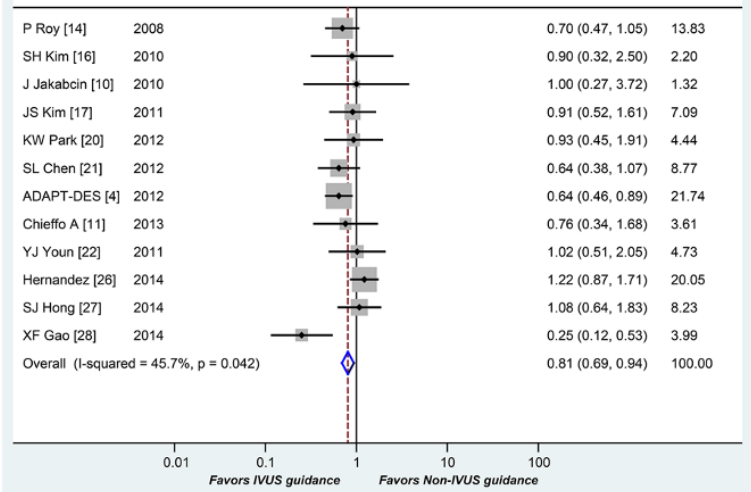

B

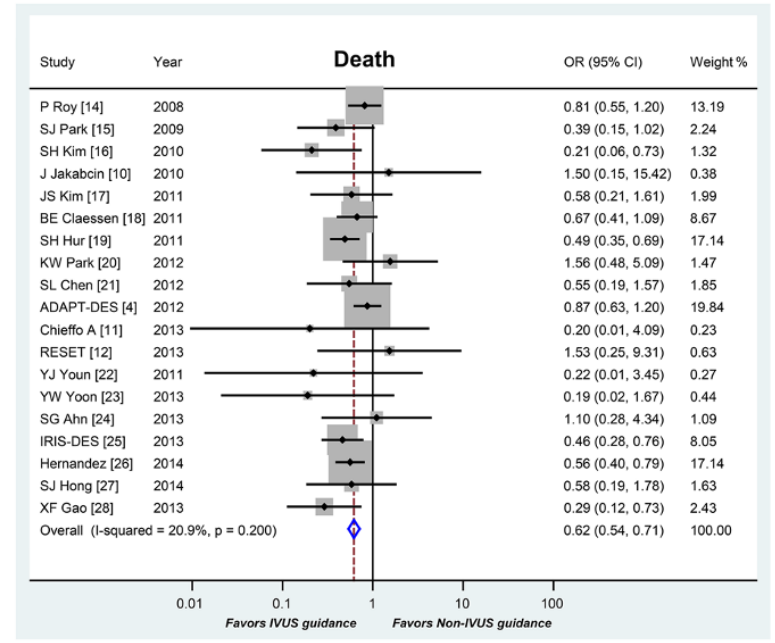

D

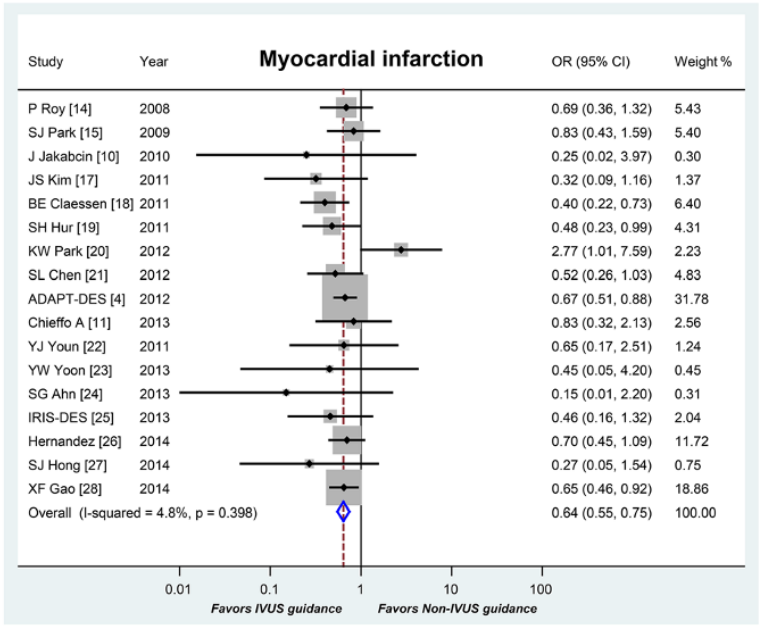

F

\begin{tabular}{|c|c|c|c|c|}
\hline Study & Year & Target vessel revascularization & OR $(95 \% \mathrm{Cl})$ & Weight \% \\
\hline P Roy [14] & 2008 & & $0.95(0.68,1.32)$ & 12.29 \\
\hline SJ Park [15] & 2009 & & $0.80(0.35,1.84)$ & 1.94 \\
\hline BE Claessen [18] & 2011 & $\rightarrow$ & $0.86(0.67,1.11)$ & 21.21 \\
\hline SH Hur [19] & 2011 & $\rightarrow$ & $1.15(0.90,1.47)$ & 22.46 \\
\hline KW Park [20] & 2012 & & $0.95(0.51,1.77)$ & 3.46 \\
\hline SL Chen [21] & 2012 & & $0.66(0.46,0.95)$ & 9.96 \\
\hline ADAPT-DES [4] & 2012 & & $0.60(0.28,1.29)$ & 2.33 \\
\hline Chieffo A [11] & 2013 & & $0.59(0.29,1.21)$ & 2.63 \\
\hline RESET [12] & 2013 & & $0.66(0.31,1.41)$ & 2.36 \\
\hline YJ Youn [22] & 2011 & & $0.89(0.50,1.57)$ & 4.17 \\
\hline YW Yoon [23] & 2013 & & $1.34(0.64,2.80)$ & 2.48 \\
\hline IRIS-DES [25] & 2013 & & $0.72(0.43,1.19)$ & 5.30 \\
\hline SJ Hong [27] & 2014 & & $0.98(0.61,1.57)$ & 6.08 \\
\hline XF Gao [28] & 2014 & $\rightarrow-$ & $0.28(0.15,0.53)$ & 3.34 \\
\hline \multicolumn{3}{|c|}{ Overall (1-squared $=46.6 \%, p=0.028)$} & $0.86(0.77,0.97)$ & 100.00 \\
\hline
\end{tabular}

Fig. 2 Clinical outcomes after DES implantation with IVUS versus angiography guidance. Abbreviation: MACE = major adverse cardiac events; $\mathrm{OR}=$ odds ratios; $\mathrm{Cl}=$ confidence intervals 


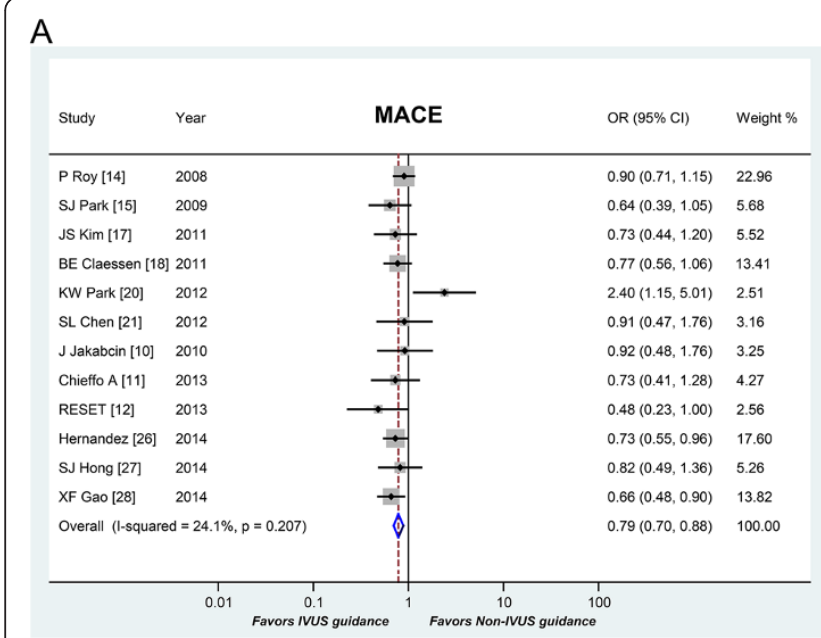

B

C

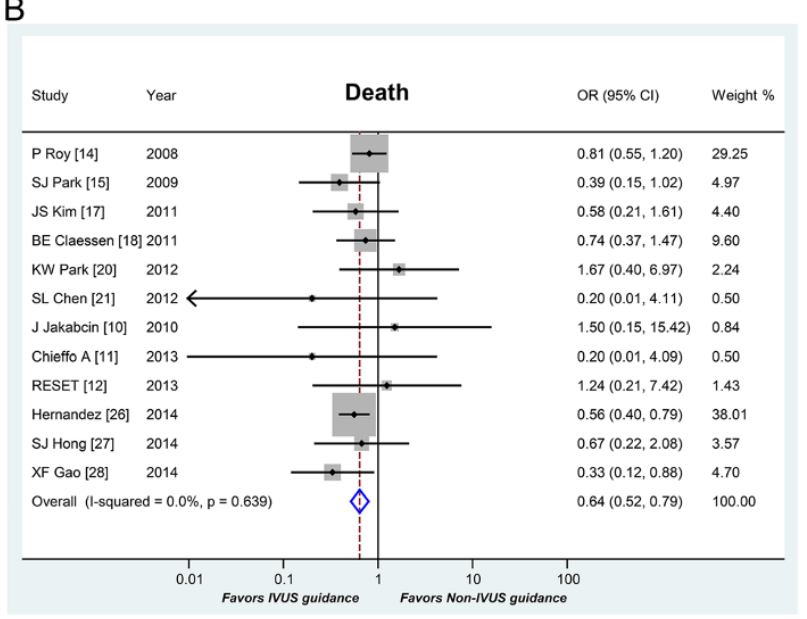

D
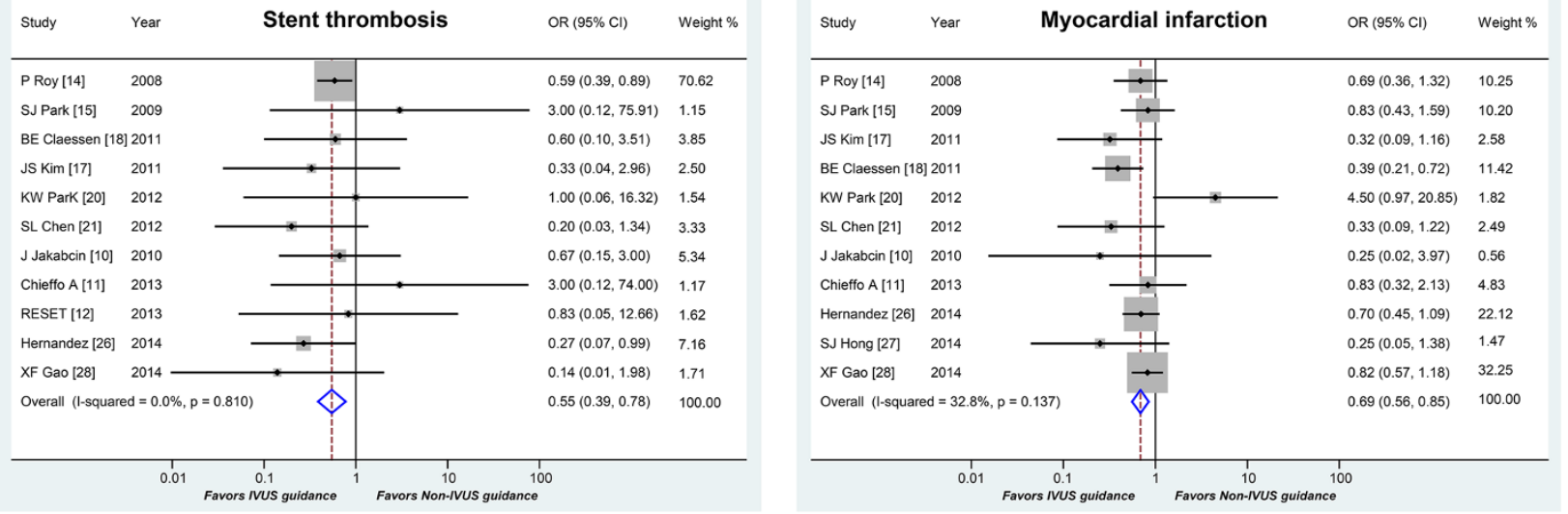

E

F

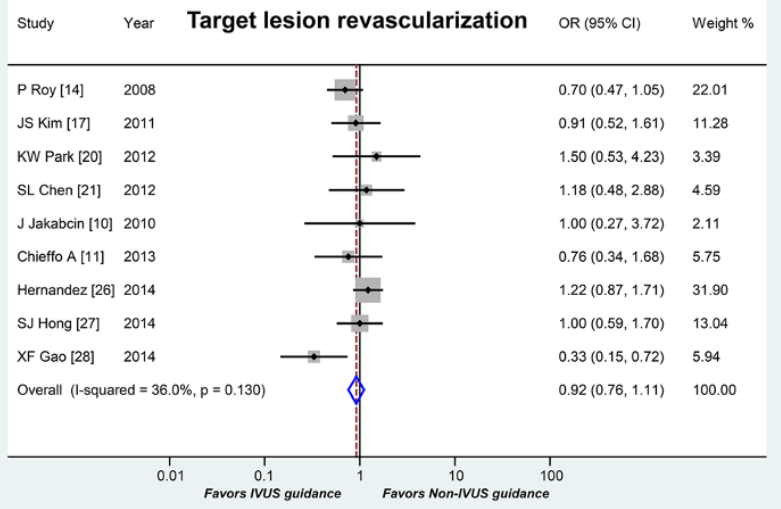

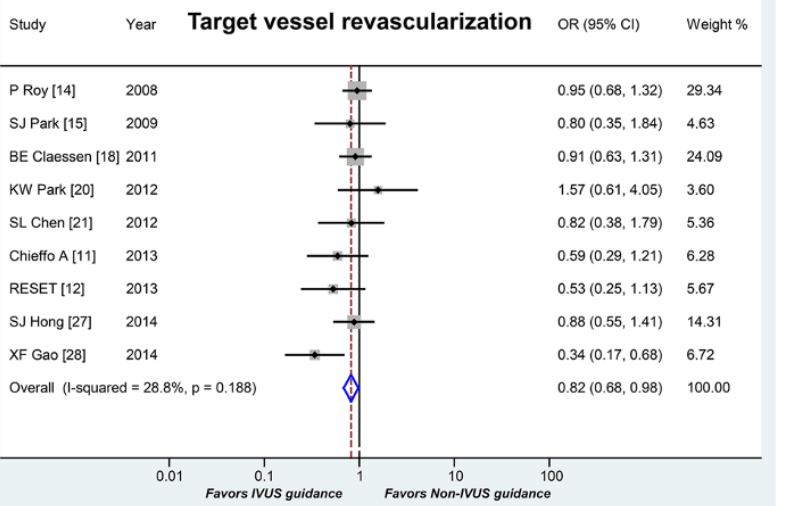

Fig. 3 Outcomes in propensity-matched and randomized studies. Abbreviation: MACE = major adverse cardiac events; OR=odds ratios; $\mathrm{Cl}=$ confidence intervals

(Fig. 4). By employing meta-regression analysis, the benefit of IVUS guidance is significantly pronounced in patients with complex lesions or ACS with respect to death $(p=$ 0.048).

\section{Sensitivity analyses and publication bias}

Sensitivity analyses of the lesion subsets did not change the reported results. There was no evidence of publication bias through the Egger's linear regression analysis 


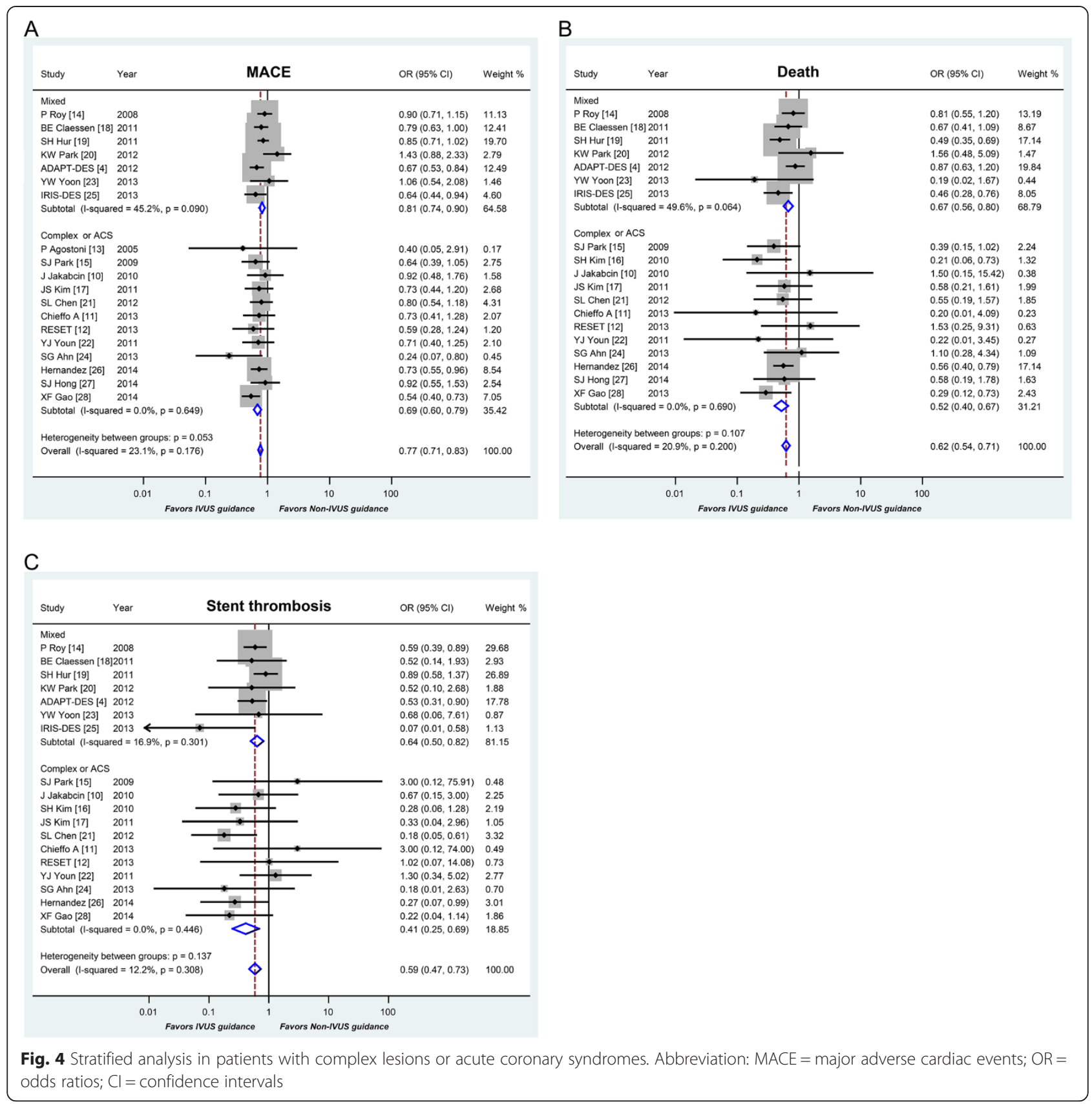

( $p=0.455$ for MACE, $p=0.395$ for death, $P=0.217$ for ST, $p=0.319$ for MI, $p=0.738$ for TLR, $P=0.103$ for TVR, Fig. 5). Assessment of publication bias using the logarithm of relative risk showed a symmetric funnel plot and confirmed no evidence of publication bias.

\section{Discussion}

This meta-analysis involving 29,068 patients has shown that IVUS guidance for DES implantation was associated with significantly improved clinical outcomes, when compared with angiography guidance. Similar results were observed in the repeated-analyses of matched and randomized studies. IVUS guidance appeared to have a more beneficial effect in patients with complex lesions or ACS than patients with mixed lesions or presentations with respect to death.

The value of IVUS in guiding DES implantation is still controversial. IVUS-guided PCI could result in larger minimum luminal diameter (MLD) and reduce the incidence of strut malapposition, but does not appear to improve clinical outcomes compared to angiography guidance [11], especially in patients with simple lesions. The lack of robust evidence supporting the value of IVUS imaging as well as the fact that IVUS increases 


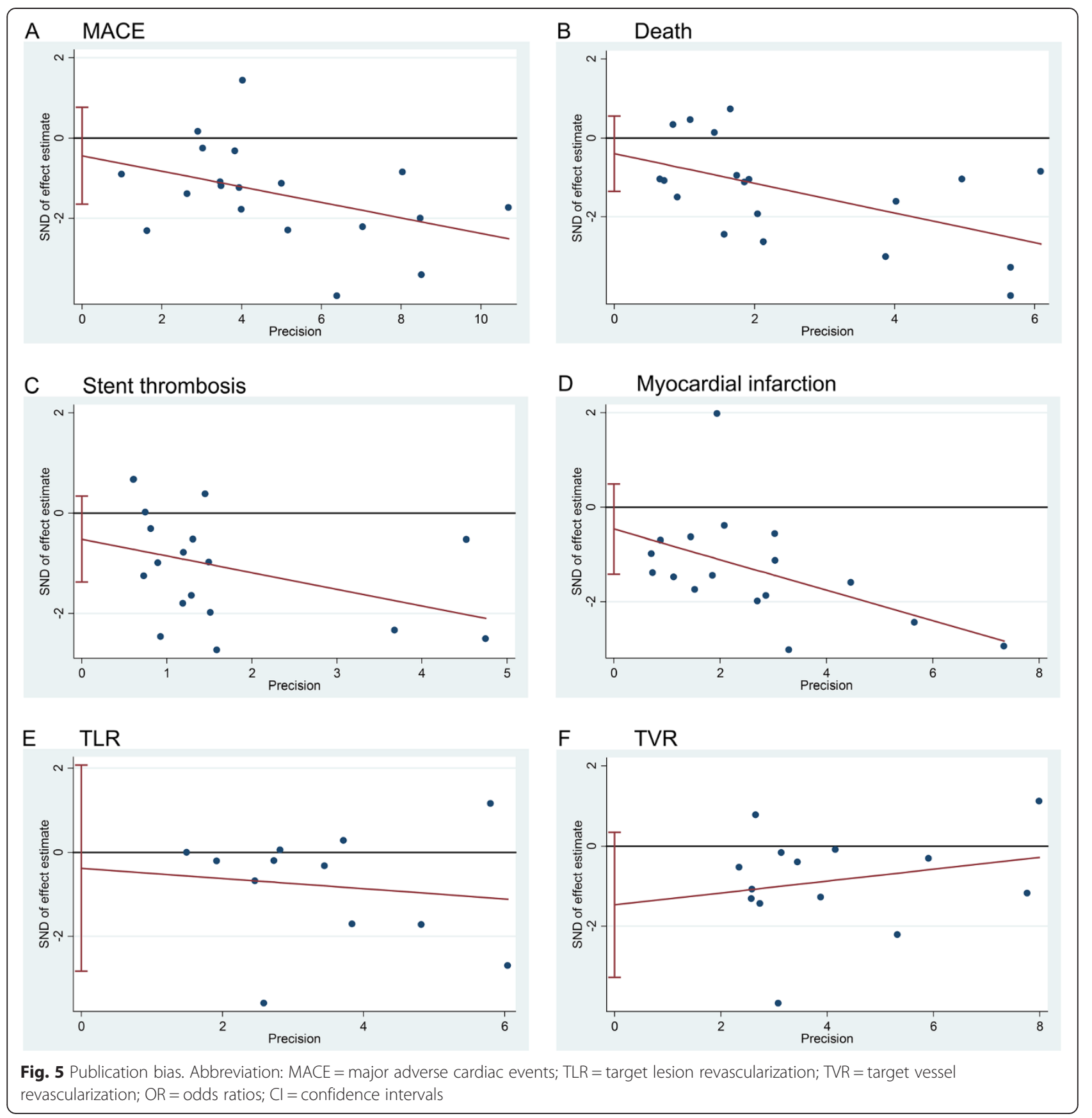

considerably procedure time and cost have restricted the clinical applications of this modality. However, recent meta-analyses comparing outcomes between patients undergoing IVUS-guided PCI versus patients undergoing angiography-guided PCI have showed significantly low rate of MACE, in the IVUS-guided group [7]. The results reported in the present analysis are agreement with those reported in previous studies, showing that IVUS may play a fundamental role in the treatment of patients with coronary artery disease as it significantly reduces clinical adverse events.
Potential differences in the baseline characteristics of the patients recruited in each study are likely to introduce bias and affect the reported results. To address this limitation we performed repeated analysis in propensitymatched and randomized populations. Of note, the repeated results confirmed that IVUS guidance increased safety and efficacy during the PCI. In the randomized AVIO trial [11], the occurrence of cumulative MACE in the IVUS guided group was apparently lower than the angiography guided group (16.9 \% vs. $23.2 \%)$ at 2 years follow-up. Although the study failed to show statistical 
significant differences in this composite endpoint, this should be predominantly attributed to the limited sample size $(n=284)$.

In the present meta-analysis we found an increased beneficial effect of IVUS guidance in complex lesions and in patients admitted with ACS with respect to death. Similarly, in the substudy of ADAPT-DES (Assessment of Dual Antiplatelet Therapy With Drug-Eluting Stents), the benefits of IVUS in reducing MACE were more evident in patients with ACS and complex lesions [4]. Indeed, IVUS is recommended for sizing bifurcation stents and evaluating lesion severity in the consensus documents from European bifurcation club [34]. Apart from this, IVUS also has an accurate correlation between IVUS derived minimal area and fractional flow reserve (FFR) to facilitate detection of hemodynamically significant left main lesions [35]. A recent large registry that recruited patients who had unprotected left main PCI showed that IVUS guidance was associated with significant reductions of 1-year cardiac death (1.7 \% vs.5.2 \%, $p=0.023)$, TVR ( $3.4 \%$ vs. $10.0 \%, p=0.002)$ and MACE (16.2\% vs. $24.4 \%, p=0.014)$ [28]. Consistently, a recent study from Europe also showed a low rate of MACE $(11.7 \%$ vs. $16 \%, p=0.04)$ in patients with left main coronary disease having IVUS guided PCI [26]. In the present sub-group analysis for patients with complex lesions or ACS, we included studies with IVUS guided PCI for left main stem disease, bifurcation, CTO, small vessel, long lesion, and ACS. Although some studies have also reported opposing results, there was a significant favorable effect of IVUS guidance on clinical outcomes in this subset of patient populations [24, 25,28].

Recently, Fröhlich GM et al. reported the long-term survival of a large cohort study (Angiography versus IVUS or intracoronary pressure wire-derived measurements of FFR to guide elective or urgent PCI) in patients undergoing PCI at eight London centers between 2004 and $2011(n=41,688)$ [5]. Surprisingly, patients who underwent IVUS had a higher adjusted mortality compared with angiography guided PCI (hazard ratio: 1.39; 95 \% CI: $1.09-1.78 ; P=0.009$ ), although this difference was no longer statistically significant in a matched pair of 803 patients. Obviously, the adjusted analysis is likely to introduce an error; in addition the absence of important procedural and lesion characteristics which may have a critical impact on clinical outcomes did not allow drawing safe conclusions. Moreover, the absence of prespecified criteria for IVUS imaging is also likely to have affected the reported results. These limitations could potentially explain the discrepancy noted between this study and our analysis which included a large sample size, the sub-analysis of matched and randomized studies, and the stratified analysis on complex lesions or ACS, which showed that IVUS guided PCI reduces death, ST, and MACE at a mean weighted follow-up of 20.8 months.

The results of the present meta-analysis and the inconsistent findings of previous studies underscore the need to design a large randomized control trial that would have enough power to investigate the efficacy of IVUS guided PCI in the $2^{\text {nd }}$ generation DES era. Certainly, a cost-effectiveness analysis of IVUS use during PCI should be incorporated into the additional benefit on clinical outcomes.

\section{Limitations}

Our study has several limitations. It is a meta-analysis and shares the limitations from the original studies. The inability to adjust the baseline characteristics between the 2 studied groups may introduce remarkable bias. However, the findings consistently showed that IVUS guidance was associated with improved outcomes in the all included studies and the repeated analysis that included matched and randomized studies. The current study was not able to differentiate the impact of IVUS guidance in patients treated with either first or newer generation DES.

\section{Conclusions}

IVUS guided PCI was associated with better clinical outcomes than angiography guided DES implantation. The benefit appeared more significant in the subgroup of patients with complex lesions or ACS with respect to death. Large scale randomized control trials are needed to identify which types of lesion morphology and subgroups of patients will be associated with better clinical outcomes after the IVUS guided DES implantation.

\section{Abbreviations}

IVUS: Intravascular ultrasound; DES: Drug-eluting stents; OR: Odds ratios; Cl: Confidence intervals; ST: Stent thrombosis; ADAPT-DES: Assessment of Dual Antiplatelet Therapy With Drug-Eluting Stents; MI: Myocardial infarction; MACE: Major adverse cardiac events; PCl: Percutaneous coronary intervention; ACS: Acute coronary syndromes; PRISMA: Preferred Reporting Items for Systematic Reviews and Meta-analyses; BMS: Bare metal stents; NOS: Newcastle-Ottawa-Scale; TVR: Target vessel revascularization; TLR: Target lesion revascularization; CTO: Chronic total occlusion; MLD: Minimum luminal diameter; FFR: Fractional flow reserve.

\section{Competing interests}

All authors have no conflicts of interest to declare.

\section{Authors' contributions}

ZYJ: Study design, literature search, data extraction, statistical analysis and manuscript writing; PS: Study design, Literature search, data extraction, statistical analysis and manuscript writing; CXY: Study design, data extraction and statistical analysis; DSJ: Statistical analysis; CSL is responsible for the overall content as the guarantor. All authors read and approved the final manuscript.

\section{Acknowledgement}

This research received no grant from any funding agency in the public, commercial or not-for-profit sectors. 


\section{Author details}

'Department of Cardiology, Nanjing First Hospital, Nanjing Medical University, Nanjing, China. ${ }^{2}$ Medical School of Southeast University, Nanjing, China. ${ }^{3}$ University College of London Hospital NHS Foundation Trust, University College of London, London, UK. ${ }^{4}$ Department of the Joint and Bone Surgery, Yantaishan hospital, Yantai, Shandong province, China. ${ }^{5}$ University of Sheffield, Sheffield, UK. ${ }^{6}$ Andreas Gruentzig Cardiovascular Center, Emory University School of Medicine, Atlanta, GA, USA. ${ }^{7}$ Department of Cardiology, Fu Wai Hospital, National Center for Cardiovascular Diseases, Chinese Academy of Medical Science, Beijing, China. ${ }^{8}$ Nanjing First Hospital, Nanjing Medical University, No. 68, Changle Road, 210006 Nanjing, Jiangsu, China.

Received: 11 May 2015 Accepted: 6 November 2015

Published online: 17 November 2015

\section{References}

1. Serruys PW, Farooq V, Kalesan B, de Vries T, Buszman P, Linke A, et al. Improved safety and reduction in stent thrombosis associated with biodegradable polymer-based biolimus-eluting stents versus durable polymer-based sirolimus-eluting stents in patients with coronary artery disease: final 5-year report of the LEADERS (Limus Eluted From A Durable Versus ERodable Stent Coating) randomized, noninferiority trial. JACC Cardiovasc Interv. 2013:6:777-89.

2. Windecker S, Kolh P, Alfonso F, Collet JP, Cremer J, Falk V, et al. 2014 ESC/EACTS Guidelines on myocardial revascularization. Eurolntervention. 2015;10:1024-94

3. Amsterdam EA, Wenger NK, Brindis RG, Casey DE Jr, Ganiats TG, Holmes DR Jr, et al. 2014 AHA/ACC Guideline for the Management of Patients With Non-ST-Elevation Acute Coronary Syndromes: Executive Summary: A Report of the American College of Cardiology/American Heart Association Task Force on Practice Guidelines. Circulation 2014;130:2354-94.

4. Witzenbichler B, Maehara A, Weisz G, Neumann FJ, Rinaldi MJ, Metzger DC, et al. Relationship between intravascular ultrasound guidance and clinical outcomes after drug-eluting stents: the assessment of dual antiplatelet therapy with drug-eluting stents (ADAPT-DES) study. Circulation. 2014;129:463-70.

5. Frohlich GM, Redwood S, Rakhit R, MacCarthy PA, Lim P, Crake T, et al. Long-term Survival in Patients Undergoing Percutaneous Interventions With or Without Intracoronary Pressure Wire Guidance or Intracoronary Ultrasonographic Imaging: A Large Cohort Study. JAMA Intern Med. 2014; 174:1360-6.

6. Zhang Y, Farooq V, Garcia-Garcia HM, Bourantas CV, Tian N, Dong S, et al. Comparison of intravascular ultrasound versus angiography-guided drug-eluting stent implantation: a meta-analysis of one randomised trial and ten observational studies involving 19,619 patients. Eurolntervention. 2012;8:855-65.

7. Ahn JM, Kang SJ, Yoon SH, Park HW, Kang SM, Lee JY, et al. Meta-analysis of outcomes after intravascular ultrasound-guided versus angiography-guided drug-eluting stent implantation in 26,503 patients enrolled in three randomized trials and 14 observational studies. Am J Cardiol. 2014;113:1338-47.

8. J Jang JS, Song YJ, Kang W, Jin HY, Seo JS, Yang TH, et al. Intravascular ultrasound-guided implantation of drug-eluting stents to improve outcome: a meta-analysis. JACC Cardiovasc Interv. 2014;7:233-43.

9. Walther S, Schuetz GM, Hamm B, Dewey M. [Quality of reporting of systematic reviews and meta-analyses: PRISMA (Preferred Reporting Items for Systematic reviews and Meta-Analyses)]. Rofo. 2011;183:1106-10.

10. Jakabcin J, Spacek R, Bystron M, Kvasnak M, Jager J, Veselka J, et al. Long-term health outcome and mortality evaluation after invasive coronary treatment using drug eluting stents with or without the IVUS guidance. Randomized control trial. HOME DES IVUS. Catheter Cardiovasc Interv. 2010;75:578-83.

11. Chieffo A, Latib A, Caussin C, Presbitero P, Galli S, Menozzi A, et al. A prospective, randomized trial of intravascular-ultrasound guided compared to angiography guided stent implantation in complex coronary lesions: the AVIO trial. Am Heart J. 2013;165:65-72.

12. Kim JS, Kang TS, Mintz GS, Park BE, Shin DH, Kim BK, et al. Randomized comparison of clinical outcomes between intravascular ultrasound and angiography-guided drug-eluting stent implantation for long coronary artery stenoses. JACC Cardiovasc Interv. 2013;6:369-76.

13. Agostoni P, Valgimigli M, Van Mieghem CA, Rodriguez-Granillo GA, Aoki J, Ong AT, et al. Comparison of early outcome of percutaneous coronary intervention for unprotected left main coronary artery disease in the drug-eluting stent era with versus without intravascular ultrasonic guidance. Am J Cardiol. 2005;95:644-7.

14. Roy P, Steinberg DH, Sushinsky SJ, Okabe T, Pinto STL, Kaneshige K, et al. The potential clinical utility of intravascular ultrasound guidance in patients undergoing percutaneous coronary intervention with drug-eluting stents. Eur Heart J. 2008:29:1851-7.

15. Park SJ, Kim YH, Park DW, Lee SW, Kim WJ, Suh J, et al. Impact of intravascular ultrasound guidance on long-term mortality in stenting for unprotected left main coronary artery stenosis. Circ Cardiovasc Interv. 2009;2:167-77.

16. Kim SH, Kim YH, Kang SJ, Park DW, Lee SW, Lee CW, et al. Long-term outcomes of intravascular ultrasound-guided stenting in coronary bifurcation lesions. Am J Cardiol. 2010;106:612-8.

17. Kim JS, Hong MK, Ko YG, Choi D, Yoon JH, Choi SH, et al. Impact of intravascular ultrasound guidance on long-term clinical outcomes in patients treated with drug-eluting stent for bifurcation lesions: data from a Korean multicenter bifurcation registry. Am Heart J. 2011;161:180-7.

18. Claessen BE, Mehran R, Mintz GS, Weisz G, Leon MB, Dogan O, et al. Impact of intravascular ultrasound imaging on early and late clinical outcomes following percutaneous coronary intervention with drug-eluting stents. JACC Cardiovasc Interv. 2011;4:974-81.

19. Hur SH, Kang SJ, Kim YH, Ahn JM, Park DW, Lee SW, et al. Impact of intravascular ultrasound-guided percutaneous coronary intervention on long-term clinical outcomes in a real world population. Catheter Cardiovasc Interv. 2013;81:407-16.

20. Park KW, Kang SH, Yang HM, Lee HY, Kang HJ, Cho YS, et al. Impact of intravascular ultrasound guidance in routine percutaneous coronary intervention for conventional lesions: data from the EXCELLENT trial. Int J Cardiol. 2013;167:721-6.

21. Chen SL, Ye F, Zhang JJ, Tian NL, Liu ZZ, Santoso T, et al. Intravascular ultrasound-guided systematic two-stent techniques for coronary bifurcation lesions and reduced late stent thrombosis. Catheter Cardiovasc Interv. 2013; 81:456-63.

22. Youn YJ, Yoon J, Lee JW, Ahn SG, Ahn MS, Kim JY, et al. Intravascular ultrasound-guided primary percutaneous coronary intervention with drugeluting stent implantation in patients with ST-segment elevation myocardial infarction. Clin Cardiol. 2011;34:706-13.

23. Yoon YW, Shin S, Kim BK, Kim JS, Shin DH, Ko YG, et al. Usefulness of intravascular ultrasound to predict outcomes in short-length lesions treated with drug-eluting stents. Am J Cardiol. 2013;112:642-6.

24. Ahn SG, Yoon J, Sung JK, Lee JH, Lee JW, Youn YJ, et al. Intravascular ultrasound-guided percutaneous coronary intervention improves the clinical outcome in patients undergoing multiple overlapping drug-eluting stents implantation. Korean Circ J. 2013;43:231-8.

25. Ahn JM, Han S, Park YK, Lee WS, Jang JY, Kwon CH, et al. Differential prognostic effect of intravascular ultrasound use according to implanted stent length. Am J Cardiol. 2013;111:829-35.

26. de la Torre Hernandez JM, Baz AJA, Gomez HJA, Alfonso MF, Garcia CT, de Carlos FG, et al. Clinical impact of intravascular ultrasound guidance in drug-eluting stent implantation for unprotected left main coronary disease: pooled analysis at the patient-level of 4 registries. JACC Cardiovasc Interv. 2014;7:244-54.

27. Hong SJ, Kim BK, Shin DH, Kim JS, Hong MK, Gwon HC, et al. Usefulness of Intravascular Ultrasound Guidance in Percutaneous Coronary Intervention With Second-Generation Drug-Eluting Stents for Chronic Total Occlusions (from the Multicenter Korean-Chronic Total Occlusion Registry). Am J Cardiol. 2014;114:534-40.

28. Gao XF, Kan J, Zhang YJ, Zhang JJ, Tian NL, Ye F, et al. Comparison of one-year clinical outcomes between intravascular ultrasound-guided versus angiography-guided implantation of drug-eluting stents for left main lesions: a single-center analysis of a 1,016-patient cohort. Patient Prefer Adherence. 2014;8:1299-309.

29. Biondi-Zoccai GG, Abbate A, Agostoni P, Testa L, Burzotta F, Lotrionte M, et al. Long-term benefits of an early invasive management in acute coronary syndromes depend on intracoronary stenting and aggressive antiplatelet treatment: a metaregression. Am Heart J. 2005;149:504-11.

30. Jadad AR, Moore RA, Carroll D, Jenkinson C, Reynolds DJ, Gavaghan DJ, et al. Assessing the quality of reports of randomized clinical trials: is blinding necessary. Control Clin Trials. 1996;17:1-12.

31. Higgins J, Green S: Cochrane handbook for systematic reviews ofinterventions (version 5.0.1). Cochrane Collaboration 2009. http://www.cochrane-handbook.org/. 
32. Parmar MK, Torri V, Stewart L. Extracting summary statistics to perform meta-analyses of the published literature for survival endpoints. Stat Med. 1998;17:2815-34.

33. Egger M, Davey SG, Schneider M, Minder C. Bias in meta-analysis detected by a simple, graphical test. BMJ. 1997;315:629-34.

34. Lassen JF, Holm NR, Stankovic G, Lefevre T, Chieffo A, Hildick-Smith D, et al Percutaneous coronary intervention for coronary bifurcation disease: consensus from the first 10 years of the European Bifurcation Club meetings. Eurolntervention. 2014;10:545-60.

35. D'Ascenzo F, Barbero U, Cerrato E, Lipinski MJ, Omede P, Montefusco A, et al. Accuracy of intravascular ultrasound and optical coherence tomography in identifying functionally significant coronary stenosis according to vessel diameter: A meta-analysis of 2,581 patients and 2,807 lesions. Am Heart J. 2015; 169:663-73.

\section{Submit your next manuscript to BioMed Central and take full advantage of:}

- Convenient online submission

- Thorough peer review

- No space constraints or color figure charges

- Immediate publication on acceptance

- Inclusion in PubMed, CAS, Scopus and Google Scholar

- Research which is freely available for redistribution 